\title{
Heuristic framework design in the field of digital literacy: A case study based on the Mozilla Web Literacy Map.
}

\author{
Daniel Domínguez Figaredo \\ National Distance Education University (UNED), Faculty of Education, Madrid, Spain // \\ ddominguez@edu.uned.es \\ M. ${ }^{a}$ Paz Trillo Miravalles \\ National Distance Education University (UNED), Faculty of Education, Madrid, Spain // \\ mptrillo@edu.uned.es
}

\begin{abstract}
:
The use of skill frameworks has become commonplace in the field of digital literacy. These frameworks are based preferentially on conceptual approaches, which leads to biases when applied in practice. Here, we present a study with an alternate focus: the skills proposed in the frameworks are connected with user behavior and heuristics are employed to group these skills. The objectives of the study were to: (1) achieve a greater coherence between the skills incorporated in these frameworks and user behavior, and (2) identify and reliably organize the clusters of skills that form frameworks. The study consisted of collecting data from a group of students about their practices within the skills of the Mozilla Web Literacy Map. The data was then grouped via factor analysis. The results were then contrasted with the initial organization of the Mozilla framework. The gap between the theoretical definition of a skill and individual behaviors was found to be more pronounced in the case of those skills whose definitions included a wider range of concepts and practices. This study opens a discussion into the scope and suitability of the method used here to generate heuristic dimensions by managing information from social behaviors.
\end{abstract}

Keywords: Heuristic method, skills frameworks, behavior based skills, theoretical biases, digital literacy.

\section{Introduction: Design limitations of digital skill frameworks}

Digital literacy is defined as a proficiency in the technologies and devices commonly found in connected societies. The range of social practices and habits that are mediated digitally are constantly expanding, therefore being digitally literate is becoming more important. As a consequence, both formal and non-formal educational institutions are offering digital literacy courses and workshops with increasing frequency.

Pre-established frameworks are used to define the competencies students should acquire in order to become digitally literate. These frameworks are also used to decide the nature of the learning content and which indicators to use in evaluating proficiency. Using these frameworks has become more common over the last few years as the use of competency-based learning approach has become widespread.

Despite their importance in education planning, competency-based frameworks are constructed using a methodology with significant limitations and biases. Competency-based frameworks are designed by first identifying the skills that should be acquired by the students. In most digital learning frameworks, this design process consists of conceptually defining these skills, using the contributions of expert panels as guide (Ferrari, 2013; Redmond, Lock, \& Smart, 
2018). However, an important criticism of the conceptual focus has been that conceptual approximations of skills are limited to the extent they are not contrasted with the behaviors that these skills represent (Eshet-Alkalai, 2004; Markauskaite, 2006; Ng, 2012). An alternate approach to defining digital skills is to contrast the authentic behaviors of technology users and their practices in open, unguided contexts. Based on the analysis of the practices, patterns of common actions are identified. In addition, skills that can be linked to these actions are identified (Anderson \& Shattuck, 2012; Viberg \& Grönlund, 2017). In this way, an understanding of user behavior is incorporated into the framework design. Most importantly, this approach puts into context the actions undertaken when acquiring digital skills.

The Mozilla Web Literacy Map (MWLM) is a well-known framework whose design is based on user practices. According to Chung and Bond (2017), the majority of the concepts embedded in the Web Literacy Map are being addressed in current digital literacies standards ${ }^{1}$. In addition the skills specifically related to web use are incorporated into this framework. Together, this makes the MWLM a suitable reference for investigating the design of digital literacy frameworks that are based on user practices. Indeed, with the goal of better understanding these digital literacy frameworks that are based on user practices, the MWLM is used in the present study as the reference for analyzing how well its definitions of skills correspond with the user behaviors within in the fields of actions of these skills.

Taking into the consideration past results (Domínguez \& Trillo, 2014; Domínguez, 2017), the objective of this study is to regroup the competencies in the Mozilla framework using a heuristic methodology based on the observed behavioral norms of a group of users. The results will clarify some of the uncertainties surrounding the skills that should form part of a framework and how to group these skills so that they correspond to empirical observations of user practices.

\section{The Web Literacy Map viewed as a practice-based framework}

Web literacy can be considered a subset of digital literacy. Achieving web literacy requires the acquisition of the set of skills necessary for using the services and functionalities that Internet graphical interfaces provide in different configurations (Belshaw \& Hilliger, 2015; Authors, 2017; Surman, 2015). The MWLM is a framework that names and defines the set of skills necessary for becoming literate. This framework relies on an approximation that is centered on user practices. The Mozilla Foundation developed a web literacy map based on the results from focus group studies and related research into educational practices. The purpose of the literacy map was to package the language and practices in order to make training in the field of web literacy more accessible. A series of focus groups were carried out to help identify which skills should be included in the map. These focus groups consisted of in-person interviews and meetings with many stakeholders, such as school teachers and educators, scientists, community

\footnotetext{
${ }^{1}$ The sample of workforce and learning standards examined to better understand what essential digital literacy skills were included or missing in the MWLM comprised the following (Chung \& Bond, 2017): American Library Association's 2011 Digital Literacy definition; Common Core State Standards and Next Generation Science Standards; International Society for Technology in Education 2016 Standards for Students; National Assessment of Educational Progress 2014 Engineering and Technology Literacy Framework; European Union's 2013 Digital Competencies Framework; United Nations Educational, Scientific and Cultural Organization's 2013 Global Media and Information Literacy Framework; Partnership for 21st Century Learning 21st Century Skills Framework; and United States Department of Education's 2016 Employability Skills Framework.
} 
members, web and technology advocates and experts, and international leaders in emerging markets and digital learning initiatives. In addition, past research into the on-the-ground educational practices of various countries was reviewed. This research had been carried out in local communities in India, Kenya, Bangladesh, and Chicago (De Reynal \& Richter, 2016; Mozilla, n.d., 2015). Finally, the map was made more applicable to purely educational contexts by establishing links between those digital skills that had been identified and included in the map and those skills that formed part of formal study plans, professional development training, credentials, and other formal and non-formal educational tools (Chung, Bond, \& O'Byrne, 2016). Taken together, this meant that a map had been developed which was accessible and that responded to the needs of a variety of stakeholders. Similar to the standards of conventional competencies, the Mozilla map can be applied in the many contexts such as curriculum design, credential schemes, professional development plans, and other initiatives for teaching people the skills they need to participate online and off.

Despite the people oriented nature of the MWLM, it has some of the same drawbacks that other educational frameworks have. According to Belshaw (2017), one of the most common errors when dealing with digital literacy (of which web literacy is a part) is to equate surface-level, procedural skills with depth of thinking and understanding. Using digital tools is believed to lead automatically to an understanding of the actions carried out. This relationship may not always hold. Issues also surround the questions of how to design skills that belong to a particular framework and how to group these skills in clusters in a way that suggests relationships between these skills. The skills that form part of the Mozilla framework stem from an analysis of user practices. Nevertheless, the framework resorts to conceptual constructs such as "read", "write", and, "participate", in order to group these skills. These notions are relics of previous versions of the MWLM. These past versions depended on a greater conceptual load in their approach to skills and the clusters used to group them (Belshaw \& Hilliger, 2015; Belshaw, Smith, \& Mozilla, 2015).

As digital experiences become more embedded in everyday life, it becomes more difficult to delimit the specific fields of action of technologically mediated social practices. Therefore, it has become increasingly necessary to develop robust theoretical and analytical frameworks to underpin research into people's digital and multimodal literacy practices.

\section{A heuristic approach to designing digital skill frameworks}

Heuristics are cognitive shortcuts that let an individual evaluate a situation on the basis of one or more basic rules. The advantage of a heuristic is that it reduces the cognitive load of making a decision based on a full evaluation of a broad and complex set of solutions while still taking into account the circumstances that arise in that context. In this study, heuristics are defined according to the bounded rationality model (Kahneman, 2003, 2012; Klaes \& Sent, 2005), and cognitive science models (Hutchins, 1995). Here, heuristics are used as methodological tools for developing competency frameworks. The objective is to develop a method for identifying and grouping skills according to a framework that corresponds to authentic behaviors.

In order to define a heuristic framework, it is necessary to analyze both people's practices and the cognitive processes that lay behind these practices. This double validation approach sidesteps the determinism that characterizes past conceptual models. In contrast to laboratory models, the theories of rationality posit that in authentic environments, multiple variables affect 
the actions that are carried out. In these cases, people apply rapid and cognitively inexpensive decision mechanisms called heuristics, in order to adapt to and exploit the contextual requirements of the environment (Evans, 2006; Gigerenzer \& Gaissmaier, 2011; March, 2002). In learning theories, behaviors are usually dimensionalized as a way of operationalizing the variables that describe a subject's performance in specific situations. For example, in the specific field of connected learning in digital spaces, heuristics and frameworks have often been used to analyze the processes underlying the student behaviors that observed in technologically mediated situations (Authors, 2014; Wang, Chen, \& Anderson, 2014).

The heuristic approach overcomes the excessively reductionist vision that is inherent to the design of these types of frameworks. It is widely accepted that, in formal skill frameworks, once a group of experts defines a competence, people that are proficient in that field will behave in accordance with that definition. However, in practice, the definition of a competence does not affect behavior so directly. People reach a threshold where their behavior matches a particular competence. They reach this threshold in a "procedural" and contextualized way. In addition, a level of proficiency is subject to certain thresholds as well (Adams \& Wu, 2002; Weinert, 2001). One issue with traditional digital literacy programs is that they tend to be based on the view that skills are separate from domain knowledge (Caulfield, 2016) ${ }^{2}$. However, domain knowledge has been shown to be a function of both prior knowledge and the capacity to apply this knowledge to new situations and contexts (Moos \& Azevedo, 2009).

\section{Research approach}

As mentioned, heuristics had not been widely explored as a method for grouping the practical activities described in the competency frameworks. Therefore a primary goal of this study was to validate the heuristic approach for designing these frameworks in the context of web literacy. Here we analyzed the relationship between the Internet behaviors of a group of users, on the one hand, and behavior-based definitions of the skill frameworks used to teach web literacy skills, on the other. The heuristic method consisted of grouping the practices that formed part of a concrete digital literacy framework and then checking for consistency between the grouping and user behavior in authentic scenarios.

The methodology was developed in three steps:

\subsection{Analysis of web practices}

In order to analyze the practices on the web, a sample of National Distance Education University graduate and undergraduate social science students was taken ( $n=193 ;$ men: 20,2\%; women: 79,8\%; age: 36,2 years). This study was approved by the University Review Board. Consent was obtained from all the participants in the study. The data was collected via questionnaire about web practices as defined by the MWLM (Chung, Bond, \& O'Byrne, 2016).

\footnotetext{
2 For example, this is true of programs that rely on checklists like CRAAP (http://ucsd.libguides.com/preuss/webeval), RADCAB ( (http://www.mhhe.com/socscience/english/allwrite3/seyler/ssite/seyler/se03/cars.mhtml).
} 
Every dimension on the questionnaire corresponded to a web-use competency. The questionnaire items referred to the skills that related to each particular competency. The items were chosen based on the criteria laid out in the MWLM (see Table 1) ${ }^{3}$.

Table 1: Questionnaire structure and dimensions.

\begin{tabular}{|c|c|}
\hline Dimensions / Competencies & Items / Skills \\
\hline 1. Read & $\begin{array}{l}\text { 1.1.1 Evaluate - Comparing information } \\
\text { 1.1.2 Evaluate - Identifying author } \\
\text { 1.2.1 Synthesize - Integrating information } \\
\text { 1.2.2 Synthesize - Combining information } \\
\text { 1.3.1 Navigate - Using hyperlinks } \\
\text { 1.3.2 Navigate - Manipulating URLs } \\
\text { 1.4.1 Search - Using search engines } \\
\text { 1.4.2 Search - Using keywords }\end{array}$ \\
\hline 2. Write & $\begin{array}{l}\text { 2.1.1 Design - Creating digital content } \\
\text { 2.1.2 Design - Modifying from feedback } \\
\text { 2.2.1 Code - Developing for problem-solving } \\
\text { 2.2.2 Code - Developing for building information } \\
\text { 2.3.1 Compose - Organizing information } \\
\text { 2.3.2 Compose - Creating web resources } \\
\text { 2.4.1 Revise - Reviewing digital content } \\
\text { 2.4.2 Revise - Evaluating the purpose of the work } \\
\text { 2.5.1 Remix - Identifying openly-licensed work } \\
\text { 2.5.2 Remix - Modifying openly-licensed work }\end{array}$ \\
\hline 3. Participate & $\begin{array}{l}\text { 3.1.1 Connect - Participating in online discussions } \\
\text { 3.1.2 Connect - Making sense of the terminology of online } \\
\text { communities } \\
\text { 3.2.1 Protect - Managing privacy of digital identity } \\
\text { 3.2.2 Protect - Understanding consequences of sharing data } \\
\text { 3.3.1 Open Practice - Distinguishing between open and closed } \\
\text { licensing } \\
\text { 3.3.2 Open Practice - Contributing using appropriate licensing } \\
\text { 3.4.1 Contribute - Connecting and learning online } \\
\text { 3.4.2 Contribute - Configuring notifications to keep up-to-date } \\
\text { 3.5.1 Share - Giving others access to digital content } \\
\text { 3.5.2 Share - Understanding the needs of audiences }\end{array}$ \\
\hline
\end{tabular}

The questionnaire contained 28 items. Responses were made on a five-point Likert scale: from 1 (strongly disagree) to 5 (strongly agree). The items had an approximately normal distribution.

\footnotetext{
${ }^{3}$ The theory underlying the Mozilla map clearly distinguishes between skills and competences. A skill is a controlled activity that a person has learned to do. Skills have objective thresholds: the skill level in a particular field can be confirmed through testing. A competency, on the other hand, is a group of skills required for a predefined purpose. Competency assessments are subjective in nature. Carrying out an assessment requires the prior definition of the criteria for considering a person "competent" in a particular subject and context (Mozilla, 2013).
} 


\subsection{Establishing heuristic patterns}

The heuristic patterns used to group the Mozilla map skills were first determined using a methodology that had previously been applied in the validation of the "familiarity heuristic" (Monin, 2003; Monin \& Oppenheimer, 2005). This methodology had also been applied in past skill frameworks that had been constructed in a way that was based on user practices (Authors, 2014; Authors, 2017). An exploratory factor analysis (EFA) was applied in order to group the variables of the questionnaire according to affinity level. The affinity level was determined in terms of statistical correlation. The factors resulting from the analysis and their composition were compared with the MWLM. Afterwards, we analyzed the correlations between the variables within the factors found to be inconsistent with the MWLM. We then explored possible explanations for these inconsistencies.

\subsection{Contrasting patterns}

The EFA patterns were contrasted with the expected MWLM patterns. The factors from the EFA grouped the user web practices according to level of correlation. The patterns were contrasted by analyzing the inconsistencies between the variables making up the factors of the questionnaire and the variables of the MWLM. Some of the EFA patterns deviated from the expected patterns. The variables of the factors that did not correspond to the expected MWLM groupings were analyzed further. Alternative models were explored by testing other possible correlations. This method was used to establish a rational criterion for grouping the skills into a framework in a way that took into account patterns in user practices and a criterion for making generalizations that could be applied to other cases.

\section{Results}

As in past studies of this type (Authors, 2017), we began with an EFA with the aim of elucidating the internal structure of the variables found in the questionnaire. The factors found in the primary dimensions of the MWLM were analyzed first. These primary dimensions were: read, write, and participate. Afterwards, a global analysis was carried out taking into account all the sub-dimensions of the framework, i.e, evaluate, synthesize, navigate, search, design, code, compose, revise, remix, connect, protect, open practice, contribute and share.

\subsection{The "Read" Dimension}

An analysis of factors in the dimension "Read" resulted in a grouping of skills that generally corresponded to the MWLM (see Table 2). However, an exception was observed with the skill "Search, using keywords". This skill weakly correlated with the factors forming part of the skills "Navigate" (.204) and "Evaluate" (.277). 
Table 2: The pattern matrix applied for the variable "Read".

\begin{tabular}{|c|c|c|c|c|}
\hline & \multicolumn{4}{|c|}{ Factor } \\
\hline & 1 & 2 & 3 & 4 \\
\hline 1.1.1 Evaluate - Comparing information & & & .526 & \\
\hline 1.1.2 Evaluate - Identifying author & & & .726 & \\
\hline 1.2.1 Synthesize - Integrating information & .572 & & & \\
\hline 1.2.2 Synthesize - Combining information & .927 & & & \\
\hline 1.3.1 Navigate - Using hyperlinks & & .510 & & \\
\hline 1.3.2 Navigate - Manipulating URLs & & .804 & & \\
\hline 1.4.1 Search — Using search engines & & & & .825 \\
\hline 1.4.2 Search — Using keywords & & .204 & .277 & \\
\hline
\end{tabular}

Note: Extraction method used: Principal Axis Factoring. Rotation method used: Promax with Kaiser Normalization. The rotation converged within 6 iterations.

An analysis of the skills subsumed under the competence "Read" revealed that "Search, using keywords" skill most strongly correlated with "Navigate, manipulating URLs" $(r=.289, p<$ .0001). In contrast, the Mozilla model stated that the skill "Search, using keywords" positively correlated with "Search, using search engines". However, in our analysis, these two variables correlated weakly $(r=.232, p<.001)$. Meanwhile, the skill "Search, using search engines" correlated moderately with the skill "Navigate, using hyperlinks" ability $(r=.410, p<.0001)$. Together, these results suggested a possible overlap between the "Search" and "Navigate" type skills. Using keywords to search and access web sites and the action of manipulating URLs could be considered both part of the same domain knowledge. A similar outcome would be expected in an analysis of the domain knowledge related to search engine use and hyperlinks.

\subsection{The Dimension "Write"}

Factoring of the variables of the dimension "Write" revealed some delocalization in some of the skills. This was especially true of the two "Design" skills (see Table 3). The variable "Design, creating digital content" was not grouped within the same factor as the "Design, modifying from feedback" variable, but instead correlated strongly with the skill "Compose" (.941). Meanwhile, the variable "Design, modifying from feedback" was isolated as a single factor (.701). 
Table 3: The pattern matrix applied for the variable "Write".

\begin{tabular}{|c|c|c|c|c|c|}
\hline & \multicolumn{5}{|c|}{ Factor } \\
\hline & 1 & 2 & 3 & 4 & 5 \\
\hline 2.1.1 Design - Creating digital content & .941 & & & & \\
\hline 2.1.2 Design — Modifying from feedback & & & & & .701 \\
\hline 2.2.1 Code — Developing for problem-solving & & & .846 & & \\
\hline 2.2.2 Code - Developing for building information & & & .787 & & \\
\hline 2.3.1 Compose - Organizing information & .519 & & & & \\
\hline 2.3.2 Compose - Creating web resources & .676 & & & .226 & \\
\hline 2.4.1 Revise — Reviewing digital content & & & & .911 & \\
\hline 2.4.2 Revise - Evaluating the purpose of the work & & .202 & & .291 & \\
\hline 2.5.1 Remix — Identifying openly-licensed work & & .953 & & & \\
\hline 2.5.2 Remix — Modifying openly-licensed work & & .651 & & & \\
\hline
\end{tabular}

Note: Extraction method used: Principal Axis Factoring. Rotation method used: Promax with Kaiser Normalization. The rotation converged within 6 iterations.

Furthermore, the skill "Design, creating digital content" most strongly correlated with the skill "Compose, creating web resources" $(r=.703, p<.0001)$. The skill "Design, modifying from feedback" correlated primarily with the skill "Revise, reviewing digital content" skill $(r=.614$, $p<.0001)$.

These results demonstrated that the creation of digital content and the creation of web resources could be defined together as a single skill lying between "Design" and "Compose". Likewise, modifying web content using information about how digital content is used and reviewed would form part of a competency that would lie between "Design" and "Revise".

\subsection{The Dimension "Participate"}

The analysis of the dimension "Participate" resulted in factors with an organization that diverged sharply from the original model. There were no factors that grouped the skills according to the MWLM (see Table 4). Factor 1 grouped the skills of "Connect", "Contribute", and "Share". Factor 2 grouped the skills of "Connect", "Protect", and "Open practice". Factor 3 grouped the skills of "Protect" and "Contribute". Factor 4 grouped the skills of "Open practice", and "Contribute". Factor 5 only consisted of the skill "Share, understanding the needs of audiences". 
Table 4: The pattern matrix applied to the variable "Participate".

\begin{tabular}{|c|c|c|c|c|c|}
\hline & \multicolumn{5}{|c|}{ Factor } \\
\hline & 1 & 2 & 3 & 4 & 5 \\
\hline 3. 1.1 Connect - Participating in online discussions & .753 & & & & \\
\hline $\begin{array}{l}\text { 3. } 1.2 \text { Connect - Making sense of online communities } \\
\text { terminology }\end{array}$ & .562 & .221 & & & \\
\hline 3.2.1 Protect - Managing privacy of digital identity & & & .748 & & \\
\hline 3.2.2 Protect - Understanding consequences of sharing data & & .792 & & & \\
\hline $\begin{array}{l}\text { 3.3.1 Open Practice - Distinguishing between open and } \\
\text { closed licensing }\end{array}$ & & .713 & & & \\
\hline $\begin{array}{l}\text { 3.3.2 Open Practice - Contributing using appropriate } \\
\text { licensing }\end{array}$ & & & & .799 & \\
\hline 3.4.1 Contribute - Connecting and learning online & .469 & & & .215 & \\
\hline $\begin{array}{l}\text { 3.4.2 Contribute - Configuring notifications to keep up-to- } \\
\text { date }\end{array}$ & .280 & & .452 & & \\
\hline 3.5.1 Share - Giving others access to digital content & .633 & & & & \\
\hline 3.5.2 Share - Understanding the needs of audiences & .801 & & & & .337 \\
\hline
\end{tabular}

Note: Extraction method used: Principal Axis Factoring. Rotation method used: Promax with Kaiser Normalization. The rotation converged within 6 iterations.

When analyzing those skills that were present in more than one factor, we found that "Connect, making sense of online communities terminology" correlated most strongly with "Share, understanding the needs of audiences" $(r=.490, p<.0001)$. The skill "Contribute, connecting and learning online" also correlated most strongly with "Share, understanding the needs of audiences" ( $r=.523, p<.0001)$. The skill "Contribute, configuring notifications to keep upto-date" correlated most profoundly with the skill "Protect, managing privacy of digital identity" ( $r=.445, p<.0001)$. Finally, the skill "Share, understanding the needs of audiences" most strongly correlated with its homolog "Share, giving others access to digital content" ( $r=$ $.575, p<.0001)$.

It was impossible to determine a consistent pattern that could be used to group skills according to their affinity with one another. The competency "Participate" contained within it a set of skills shaped by complex meanings and diverse domain fields. This complexity and diversity resulted in a high level of variability both conceptual and concrete in nature.

\section{Discussion}

The MWLM is the web skills framework that has the most practical design. However, the MWLM organizes skills in a manner that is purely conceptual, a limitation observed in most digital literacy skill frameworks. The purpose of this study was to overcome this limitation in 
framework design. A heuristic methodology was employed in this study. This methodology consisted of grouping skills in the framework as a function of web user behavior. We propose that behavioral heuristics could appropriately be used more broadly as a method for grouping the practices that are integral to frameworks.

It is important to point out that the heuristics employed do not stem from categories constructed by "experts" as is the case with usability heuristics. On the contrary, the heuristics are derived from a direct behavioral analysis of users in authentic scenarios. However, it is important to note that focusing on individuals - that is, on their practices - as opposed to taking into account the broader ecology describing situations of social interaction, could limit the value of using heuristics to compose comprehensive frameworks. Such is the case with competency frameworks (see Forlizzi, 2008 for a discussion of case of heuristic-based design).

It is also true that using heuristics to model or design frameworks can be viewed as an approximation for extremely reductionist behavior. Nevertheless, the use of heuristics permits a more granular framing of problems, as well as possible solutions, than do more conventional approaches (Lockton, Harrison, Cain, Stanton, \& Jennings, 2013). Indeed, in the case of skill frameworks, it is possible to establish a stronger link between skills and the behavior of users than is usual with conceptual approaches. This is because, in conceptual approaches, there is no reliable way to contrast the framework with how users behave in authentic situations. Nevertheless, reducing behaviors to heuristic dimensions carries the risk of oversimplification. One way to mitigate this risk would be to develop multiple levels of abstraction to describe the user behavior through data that is derived directly from observed practices. Developing these levels of abstraction would most likely be accomplished through triangulation, i.e., composing more informed representations via multiple research methods. Nevertheless, it is possible to analyze behavioral heuristics using descriptive statistics (comparing cases and correlating means) of small samples $(n<100)$. This possibility was demonstrated by the work of Monin and Oppenheimer (2005), on which this study is based.

Using factor analysis to construct heuristics is a widely validated method (Darlington, 2004; Darlington \& Hayes, 2017; Kahneman \& Frederick, 2002; Thompson, 2004). Factor analysis can also provide hints about where to find meaningful causal relationships. This is true even if we assume that it is possible to make more than one interpretation of the same factored data in the same way and that the factor analysis may fail to identify causality. The strengths and weaknesses of employing combined factorial and correlational analysis to order heuristics are also known (Wallace, 2005). This information suggests that a further analysis may be required in order to fully take into account the differences in the competency frameworks as a whole. One of the advantages of this combined method is that it not only generates information for improving the strategy of heuristic organization, but also demonstrates which problems differentially affect each strategy.

Defining the skills which should form part of a particular framework is a task which requires a more complex approximation methodology, e.g., triangulation method. If one wants to "design" a framework, for example, by grouping abilities according to rational and evidencebased criteria, then using the empirically observed user behavior as a starting point adds value. In this case, it is the design process and not the skill set which determines the framework. The framework benefits directly from research that is based on individual practices. This is one of 
the main contributions that a heuristic grouping approximation can have in the study of frameworks which promote individual web literacy.

\section{Conclusions}

Heuristics can be used to organize individual behavior patterns into nodes and dimensions that can be used to help explain these behaviors in certain contexts. When applied to the design of competency frameworks, heuristics can also help group skills by taking into consideration the actual user behavior during a particular task that requires one or more competencies. The present study provides new evidence to support this line of research. The data presented reinforce the idea that behavioral heuristics can be used to explain the way that users carry out actions associated with a particular competency and skill framework. Specifically, heuristics help design these frameworks by justifying how practices are grouped according to affinity level. Affinity level is measured in terms of correlation strength. Therefore, the projected behaviors can, in a practical (rather than merely conceptual) sense, be apportioned into skill frameworks.

The MWLM served as the reference for this study. The results revealed two tendencies. First, rational and user-based skill groupings were complicated by highly abstract skill definitions. For example, this was true for those skills subsumed under competency "participate". Second, relevant tendencies were observed with the more concrete competencies "read" and "write. The "search", "navigate", and "design" skills were grouped in a way that diverged from the Mozilla framework.

At the same time, these concrete findings are consistent with leading trends in digital literacy. In broader terms, this study confirms the difficulty of proposing digital literacy frameworks that are as robust as the classic reading/writing and math literacy frameworks (Belshaw, 2012; Olsson \& Edman-Stålbrant, 2008; Ventimiglia \& Pullman, 2016). More specifically, the ephemeral nature of technologies that support web activities and digital spaces makes it difficult to identify behaviors that are robust enough to correlate with concrete abilities and practice. This difficulty has been especially apparent among those skills that are dependent on evolving web access technologies. For example, the most unstable competency is "participate". This competency is also the one most dependent on changes in interfacing technologies and the programming codes which channel interface inputs and outputs. Likewise, the authors of the MWLM (Chung \& Bond, 2017) point out that the skills in "participate" differ the most in the context of digital literacy. As a consequence, it is difficult to identify the fields of action of completely novel skills. Chung and Bond (2017) point out the uniqueness of "open practice", however, we have found that rest of the skills in "participate" are unstable as well. The theoretical approach followed here for introducing these skills doesn't directly fit well with user web practices. This is because the behaviors do not fit precisely into the conceptual ranges of these skills. This is especially true of the "open practice" phenomenon, which facilitates the use of resources, as well as the contribution of resources. "Open practice" also leads to a more web transparent and accessible web.

More analyses using more diverse methods are doubtless necessary for validating the data collected here. Nevertheless, this study reinforces many of the presuppositions we had of using heuristic models to design competency frameworks. Significantly, new and interesting lines of inquiry have been opened in the specific field of digital literacy web skill groupings. 


\section{Data statement}

The processed data can be taken directly from the paper. For more in-depth study of the raw data of the study, please contact the authors. In the study, no personal data was requested, so it was not necessary to anonymize the data or manage them under safe conditions.

\section{References}

Adams, R., \& Wu, M. (2002). PISA 2000 Technical Report. Paris: OECD Publications. Anderson, T., \& Shattuck, J. (2012). Design-based research: a decade of progress in education research. Educational Researcher, 41(16), 16-25.

Belshaw, D. (2012). What is 'digital literacy'? A Pragmatic investigation. (Doctoral dissertation, Durham University, UK). Retrieved from http://etheses.dur.ac.uk/3446/

Belshaw, D., \& Hilliger, L. (2015). Web Literacy Map. A map of the skills and competencies people need to read, write and participate effectively on the web. Retrieved from https://wiki.mozilla.org/Learning/WebLiteracyStandard

Belshaw, D., Smith, K. L., \& Mozilla (2015). Why Mozilla cares about Web Literacy. White Paper. Retrieved from http://mozilla.github.io/webmaker-whitepaper/

Belshaw, D. (2017, April 21). Can digital literacy be deconstructed into learnable units? [Web log post]. Retrieved from http://literaci.es/deconstructed-units

Caulfield, M. A. (2016, December 19). Yes, Digital Literacy. But Which One? [Web log post]. Retrieved from https://hapgood.us/2016/12/19/yes-digital-literacy-but-which-one/

Chung, A., Bond, I., \& O’Byrne, W. I. (2016). Web Literacy 2.0. Retrieved from https://mozilla.github.io/content/web-lit-whitepaper/

Chung, A., \& Bond, I. (2017, February 11). What Web Literacy Skills are Missing from Learning Standards? [Web log post]. Retrieved from https://medium.com/read-writeparticipate/what-essential-web-skills-are-missing-from-current-learning-standards-

$66 \mathrm{e} 1 \mathrm{~b} 6 \mathrm{e} 99 \mathrm{c} 72$

Darlington, R. B. (2004). Factor Analysis. Retrieved from http://node101.psych.cornell.edu/Darlington/factor.htm

Darlington, R. B., \& Hayes, A. F. (2017). Regression analysis and linear models: Concepts, applications, and implementation. New York, NY: Guilford Press.

De Reynal, L., \& Richter, B. (2016). Stepping Into Digital Life. The Digital Skills Observatory Research Report. Retrieved from http://mzl.la/dso-final-report

Domínguez, D., \& Trillo, P. (2014). Learning Competences in Open Mobile Environments: A Comparative Analysis Between Formal and Non-Formal Spaces. Open Praxis, 6(3), 235-244. http://dx.doi.org/10.5944/openpraxis.6.3.131

Domínguez, D. (2017). Heuristics and Web Skills Acquisition in Open Learning Environments. Journal of Educational Technology \& Society, 20 (4), 102-111. Retrieved from https://www.jets.net/ETS/journals/20 4/10.pdf

Eshet-Alkalai, Y. (2004). Digital literacy: a conceptual framework for survival in the digital era. Journal of Multimedia and Hypermedia, 13(1), 93-106.

Evans, J. (2006). The heuristic-analytical theory of reasoning: extension and evaluation. Psychonomic Bulletin \& Review, 13(3), 378-395. 
Ferrari, A. (2013). DIGCOMP: A Framework for Developing and Understanding Digital Competence in Europe. Luxembourg: Publications Office of the European Union. https://doi.org/10.2788/52966

Forlizzi, J. (2008). The product ecology: Understanding social product use and supporting design culture. International Journal of Design, 2(1), 11-20.

Gigerenzer, G., \& Gaissmaier, W. (2011). Heuristic Decision Making. Annual Review of Psychology, 62, 451-482. https://doi.org/10.1146/annurev-psych-120709-145346

Hutchins, E. (1995). Cognition in the Wild. Cambridge, MA: The MIT Press.

Kahneman, D., \& Frederick, S. (2002). Representativeness Revisited: Attribute Substitution in Intuitive Judgment. In T. Gilovich, D. Griffin, \& D. Kahneman (Eds.), Heuristics and Biases: The Psychology of Intuitive Judgment (pp. 49-81). New York: Cambridge University Press.

Kahneman, D. (2003). A perspective on judgment and choice: Mapping bounded rationality. American Psychologist, 58, 697-720.

Kahneman, D. (2012). Thinking Fast and Slow. London: Penguin Group.

Klaes, M., \& Sent, E-M. (2005). A conceptual history of the emergence of bounded rationality. History of Political Economy, 37(1), 27-59.

Lockton, D., Harrison, D. J., Cain, R., Stanton, N. A., \& Jennings, P. (2013). Exploring problem-framing through behavioural heuristics. International Journal of Design, 7(1), 37-53. Retrieved from http://ijdesign.org/ojs/index.php/IJDesign/article/view/1254/560

March, B. (2002). Heuristics as Social Tools. News Ideas in Psychology, 20, 49-57.

Markauskaite, L. (2006). Towards an integrated analytical framework of information and communications technology literacy: from intended to implemented and achieved dimensions. Information Research, 11(3), 252-280.

Monin, B. (2003). The Warm Glow Heuristic: When Liking Leads to Familiarity. Journal of Personality and Social Psychology, 85(6), 1035-1048. https://doi.org/10.1037/0022$\underline{3514.85 .6 .1035}$

Monin, B., \& Oppenheimer, D. M. (2005). Correlated Averages vs. Averaged Correlations: Demonstrating the Warm Glow Heuristic Beyond Aggregation. Social Cognition, 23(3), 257278. https://doi.org/10.1521/soco.2005.23.3.257

Moos, D. C., \& Azevedo, R. (2009). Self-efficacy and prior domain knowledge: to what extent does monitoring mediate their relationship with hypermedia learning? Metacognition and Learning, 4(3), 197-216. https://doi.org/10.1007/s11409-009-9045-5

Mozilla (n.d.). Digital Skills Observatory. Retrieved from https://mozillafoundation.github.io/digital-skills-observatory/

Mozilla (2013). Mozilla Web Literacies white paper. Retrieved from https://wiki.mozilla.org/Learning/WebLiteracyStandard/Legacy/WebLiteraciesWhitePaper Mozilla (2015). A Locally Relevant Web Early Research \& Recommendations. Retrieved from https://webmaker-dist.s3.amazonaws.com/reports/research.pdf

Ng, W. (2012). Can we teach digital natives digital literacy? Computers \& Education, 59(3), 1065-1078. https://doi.org/10.1016/j.compedu.2012.04.016

Olsson, L., \& Edman-Stålbrant, E. (2008). Digital literacy as a challenge for Teacher Education. Implications for educational frameworks and learning environments. In M. Kendall \& B. Samways (Eds.), Learning to Live in the Knowledge Society (pp. 11-18). Boston: Springer. 
Redmond, P., Lock, J. V., \& Smart, V. (2018). Pre-service teachers' perspectives of cyberbullying. Computers \& Education, 119, 1-13. https://doi.org/10.1016/j.compedu.2017.12.004

Surman, M. (2015, June 3). The essence of web literacy [Web log post]. Retrieved from https://marksurman.commons.ca/2015/06/03/the-essence-of-web-literacy/

Thompson, B. (2004). Exploratory and confirmatory factor analysis: Understanding concepts and applications. Washington, DC: American Psychological Association.

Viberg, O., \& Grönlund, Å. (2017). Understanding students' learning practices: challenges for design and integration of mobile technology into distance education. Learning, Media and Technology, 42(3), 357-377. https://doi.org/10.1080/17439884.2016.1088869

Ventimiglia, P., \& Pullman, G. (2016). From Written to Digital: The New Literacy. EDUCAUSE review, 51(2). Retrieved from https://er.educause.edu/articles/2016/3/fromwritten-to-digital-the-new-literacy

Wallace, R. J. (2005). Factor Analytic Studies of CSP Heuristics. In P. Van Beek (Ed.), Principles and Practice of Constraint Programming - CP 2005 (pp. 712-726). Berlin: Springer.

Wang, Z., Chen, L., \& Anderson, T. (2014). A framework for interaction and cognitive engagement in connectivist learning contexts. The International Review of Research in Open and Distance Learning, 15(2). Retrieved from http://www.irrodl.org/index.php/irrodl/article/view/1709/2838

Weinert, F. (2001). Concept of competence: a conceptual clarification. In D. S. Rychen \& L. H. Salganik (Eds.), Defining and Selecting Key Competencies (pp. 45-66). Gottingen: Hogrefe $\&$ Huber Publishers. 